\title{
Research on the Implementation of Human Resource Cost Management and Performance Pay in Colleges
}

\author{
Song Jinhua \\ Jiangsu Maritime Institute \\ NanJing, China \\ 453344933@qq.com
}

\begin{abstract}
To implement human resource cost management and establish a fair performance appraisal system in colleges, this paper analyzes the relationship between the performance appraisal and the cost of human resources, expounds the incentive function of performance pay in establishing a fair salary system. After an in-depth analysis, this paper finds 1)the combination of a fair salary system and human resource cost control is the foundation of managing human resources cost in colleges; 2)a reasonable accounting method of human resource cost is the precondition of implementing performance pay; 3)colleges still need to further improve the incentive systems and restraint mechanisms at present.
\end{abstract}

Keywords-colleges; performance pay; human resource cost; management

\section{INTRODUCTION}

As a place gathering high-level talents, colleges shoulder great responsibilities of imparting knowledge, inheriting culture, training personnel and serving society. The teaching work in colleges is becoming more and more specialized, but the management mechanism of teachers' work, in theory or in practice, is still customary to follow the traditional personnel management system in many aspects. Therefore, there is a dilemma in the internal system reform in colleges. In theory, it has been recognized that the management of knowledge is a complex system and cannot be quantified using the simple way in the industrial era. In practice, from the standpoint of the feasibility, quantitative method has to be used to manage. In order to get rid of the dilemma, most colleges will focus on reform of the salary system and management system construction, aiming to effectively run through the effective compensation system to protect the personnel management system and achieve the overall goal of college. Therefore, colleges have to adjust operation mechanism and strengthen management to solve the following problems: how to implement human resource cost management, establish a fair performance appraisal system and effectively combine the limited manpower, financial and material resources to promote the construction of teachers' team and play the overall advantages of teachers based on the actual resources and longterm development planning of colleges.

\section{THE RELATIONSHIP BETWEEN THE COST OF HUMAN RESOURCES AND PERFORMANCE PAY IN COLLEGES}

Human resource cost is paid in order to obtain and develop human resources which should normally include a series of fees paid in the personnel recruitment, recruitment and selection, arrangement, utilization, orientation and on-the-job training. The cost of human resources in colleges is the price paid by the college to achieve its objectives and development goals in human resources ${ }^{[1]}$. However, the cost of the college teachers is based on the cost of education rather than the output of the product or service. The breakdown of human resources cost is based on the definition of human resources cost and the subdivision of human resource cost of college teachers. The cost of human resources in colleges mainly includes five parts:

The acquisition cost of human resources: the acquisition cost of human resources is paid in the process of recruiting and hiring teachers. 2. The development cost of human resources: the development cost of human resources is to improve the ability of teachers and increase the value of human resources in the school. 3. The use of human resources cost: the use of human resources cost is paid in the process of using teachers. 4 . Human resources security cost: the cost of human resources security must be paid in the protection of human resources' subsistence temporarily or in the long term. 5. Turnover cost of human resources: turnover cost is paid due to the turnover of human resources, such as low cost of turnover and compensation cost of turnover, respectively referring to the cost of low-efficiency teaching when teachers are about to leave school and the cost of compensation when teachers have to be dismissed.

This cost of human resources in colleges referred to in this paper includes all expenditures produced in order to obtain, maintain and develop the human resources. It mainly consists of three parts: acquisition cost, maintenance cost and development cost. Acquisition cost is paid in order to obtain a certain human resource, including recruitment and selection. Maintenance cost refers to the expenses paid during employing the staff, including wages and welfare. Development cost is paid in order to improve the quality of staff, including training expenditure. Performance pay is also known as performance related wages or salary, which is to establish a system of association according to the teachers' task and work 
performance. It aims to distinguish between the mediocrity and excellence of teaching and inspire teachers to pursue outstanding work results. It is actually a kind of contract salary system and a typical salary system in western countries such as the United States, which is characterized by the growth of the salary depending on the performance of teaching work. The performance pay is different from bonuses, which is generally reflected in the long-term salary growth. Performance pay, as well as job promotion and tenure, is linked to the assessment of teachers' performance ${ }^{[2]}$. As a part of performance salary system, performance pay belongs to the category of maintenance cost, pays more attention to the investment effect assessment of human resources cost, which is based on the employee's performance and contribution and achieves the reward or punishment for employees.

\section{The IMPLEMENTATION OF HUMAN RESOURCE COST MANAGEMENT AND FAIR PERFORMANCE PAY IS THE KEY OF HuMAN RESOURCE MANAGEMENT IN COLLEGES}

Effectively carrying out the cost management of human resources is the common demand of both the college itself and the employed staff. For colleges, to carry out the human resource cost management is not only the correct formulation of management plans and countermeasures for colleges, but also has great reference value for the optimization of the implementation and effective management of the most important human resources. At the same time, it is able to solve the waste of resources, unfair distribution, weak incentives and other issues and provide scientific and practical basis for the implementation of mobilizing the enthusiasm and creativity of employees in colleges. And for the employees, the implementation of fair performance salary system on the one hand can stimulate the potential enthusiasm of the employees and on the other hand can minimize the human resources cost and create the most reasonable and scientific human resource system to ensure the full use of human resources in the long term. According to the survey, college teachers' income mainly consists of three aspects: fixed basic salary, post allowance and performance appraisal.

The basic salary usually refers to the combination of national unified salary and local rank wage, which mainly changes according to positional titles and national unified plan adjustment. Post allowance is mainly paid within the provisions of the duties (title, post) in colleges, which is relatively fixed during the term of employment and directly affects the teacher's income and incentive effect. Performance appraisal salary consists of special allowance, work remuneration, commission balance of teaching scientific research projects and the bonus of scientific research, etc. In this kind of salary system structure, the basic salary is generally not adjusted and can be classified into security factors for teachers. Post allowance and performance appraisal wages change according to time and job performance and have greater incentive for teachers. The core of performance compensation is the change of teacher's salary level with individual and team performance. In this system, teachers are paid according to their values in the teaching process as the output of college, their views of culture matching with the college development and their conducts beneficial to the realization of the strategic goal of college ${ }^{[3]}$. Therefore, the performance pay and post allowance have different emphases. Relatively speaking, post allowances provide basic protection, while performance pay plays an incentive role in the long term. When the teacher's performance can be evaluated fairly and obtain the corresponding compensation, the teacher's psychological need for the sense of justice and achievement can be satisfied simultaneously.

\section{FAIR PAY SYSTEM IS THE BASIS OF THE MANAGEMENT OF HuMAN RESOURCES COST IN COLLEGES}

The biggest resource of college is human resource, so human resources cost is the main aspect of educational cost. For a long time, the human resource as a public resource is free to be used without considering the cost, which can easily lead to the expansion of the number of teaching staff in colleges under the maximization background of the interests of the local conditions. The cost control of human resources should be based on a fair salary system so that the cost of the input is proportional to the efficiency of the creation, which cannot be narrowly understood as "human resources cost is as low as possible", because once the cost of human resources is reduced, the quality of the teaching staff will be weakened. Especially performance pay remuneration can no longer play an incentive effect, which will hit the enthusiasm of the teaching staff, reduce the working efficiency and affect the teaching potential. So, reduction in cost will produce a serious impact on vested benefits. Only by combining the scientific and reasonable salary system and the cost accounting and measuring system of human resources in colleges can be more effective to stimulate the enthusiasm of the teaching staff and improve the level of human resource management in colleges. Colleges should create a fair and transparent salary system, including the open rules, fair opportunity and distribution. Open rules refer to the openness of all the stipulations and systems in colleges. Fair opportunity refers to the fairness in providing opportunities for each teacher in colleges. Whether it is performance evaluation, promotion or other aspects, should reflect the fairness. Fair distribution is to let the teachers think that their investment return is reasonable. Teachers compare their own investment returns with others, if it is balanced, they will have more motivation to carry on the next step of work. If it is imbalanced, the enthusiasm of their work will be greatly affected. In addition, a fair environment can create a more harmonious atmosphere, so that teachers can focus on scientific research and teaching work.

\section{Reasonable Human Resource Cost Accounting And MEAsuring Methods Provide Guarantee For the IMPLEMENTATION OF PERFORMANCE PAY}

The establishment of educational cost accounting system is the basis of the human cost management in colleges. On the basis of the introduction of the specific accounting measurement methods of human resource accounting, the cost accounting and measurement methods of human resources in colleges can be established. In general, the model of human resource cost measurement has three kinds of methods, historical cost method, replacement cost method and opportunity cost method. A measurement model of human 
resource cost proposed by the professor in Yokohama National University of Japan divides the human resources cost into acquisition cost, development cost, utilization cost and replacement cost, which can be used as the reference in practice. The specific steps include:

TABLE I. COMPOSITION AND TRANSFORMATION OF HUMAN RESOURCE $\operatorname{COST}^{[4]}$

\begin{tabular}{|c|c|c|c|c|}
\hline Step 1 & Step 2 & Step 3 & Step 4 & Step 5 \\
\hline \multirow{3}{*}{$\begin{array}{c}\text { expenditure } \\
\text { on human } \\
\text { resources }\end{array}$} & $\begin{array}{l}\text { acquisition } \\
\text { cost and } \\
\text { development } \\
\text { cost }\end{array}$ & $\begin{array}{c}\text { investment to } \\
\text { individuals }\end{array}$ & $\begin{array}{c}\text { recruitment, } \\
\text { training and } \\
\text { other } \\
\text { expenses }\end{array}$ & \multirow{2}{*}{$\begin{array}{c}\text { human } \\
\text { assets }\end{array}$} \\
\hline & $\begin{array}{l}\text { acquisition } \\
\text { cost and } \\
\text { development } \\
\text { cost }\end{array}$ & $\begin{array}{l}\text { investment to } \\
\text { organizations }\end{array}$ & $\begin{array}{c}\text { organization, } \\
\text { construction } \\
\text { and } \\
\text { development } \\
\text { expenses }\end{array}$ & \\
\hline & $\begin{array}{l}\text { utilization } \\
\text { cost }\end{array}$ & \multicolumn{3}{|c|}{ expensing } \\
\hline
\end{tabular}

The human resources accounting center in colleges must report the data of human resources cost and the contribution value to the related functional department according to certain working hours. The colleges can make a comparative analysis of the data using the following methods: horizontal comparison, longitudinal comparison and comparison of plan and practice. According to the demand of evaluation of the implementation of performance pay benefits, statistical data of human resources and personnel contribution value can be compared in categories so as to find out the problems in the implementation of performance pay, optimize the financial expenditure of resources, improve the expenditure structure, adjust the focus and support object support, improve the job evaluation and performance evaluation methods, strict cost management of human resources and improve the benefit of running colleges.

\section{The Process of Implementing the Performance APPRAISAl IN COLLEGES NEEDS TO BE EXAMINED AND SUPERVISED}

In the salary system of college teachers, the basic salary and post allowance have certain stability, and the implementation process of the performance appraisal salary needs to be supervised. We should see that the setting and implementation of the performance appraisal of college salary embody the advantages in the following aspects: rewarding high output has incentives for teachers and improves their productivity; encouraging teachers to pursue excellence; improving school average income level; retaining the talents of high yield; reducing the teachers to find part-time job; improving teachers' team morale and attracting excellent talents of other fields to enter the college, etc.. In the 1980s, a performance pay reform literature research in an America university showed that there are problems and risks in the implementation of performance pay system. To prevent all kinds of problems in the operation, if not handled properly, it will lead to resistance and even failure in the process of reform. For example, we cannot simply emphasize economic incentives, while ignoring the mobilization of internal motivation and avoiding the weakening of the relationship among responsibility, performance and compensation. Evaluation cannot pay attention to scientific research, ignoring the teaching and service. Evaluation should not only focus on quantity but quality as well. Specifically, there are two aspects of the task of college teachers, scientific research task and teaching task. These two tasks are complementary to each other, which should be taken into full consideration in the assessment of the value of teachers in colleges. However, if the scientific performance can be measured and verified objectively, it is almost impossible to verify the teaching performance. Generally, yield can be observed, and quality is difficult to be accurately observed and verified. Therefore, the compensation system based on yield assessment (piecework) will lead teachers to improve output, without sacrificing quality. At present, disadvantages of performance evaluation and compensation system of colleges is alternative to overcome the multi task (due to the existence of unobservable performance tasks-teaching) ${ }^{[5]}$, which leads to the weakening contribution of the teachers in colleges. We believe that research and teaching are not divided in colleges, and the quality of teaching to a certain extent can be also benefited from the research. We can join the teaching work in the original scientific research performance based salary system of incentives, so as to encourage teachers to research work and keen on teaching because the scientific research and teaching tasks are complementary in performance salary system. Therefore, in the performance appraisal system, it can be based on the objective performance evaluation and supplemented by the subjective weighting (subjective evaluation of teaching and scientific research task) to carry out further design.

With the development of higher education, college personnel composition has changed a lot and personnel agency, contract and other personnel are becoming more and more, taking a considerable size and showing a continually growing trend. The reform of the performance pay system is still in accordance with the "staff design identity" in the salary system, and there is no clear national policy whether the personnel out of preparation are paid according to the application of labor contract wage system or performance wage system, which will inevitably cause the internal and nonessential personnel to be treated unequally in terms salary, and the unreasonable institutional arrangements are on contrary to the original intention of the reform of performance pay and deviated from the concept of fair distribution.

There are few existent researches of performance appraisal and distribution of supernumerary personnel at present, so how to reflect the incentive function of performance pay among the supernumerary staff and realize equality and fairness in group and supernumerary personnel in terms of income distribution and evaluation still need further research.

\section{CONCLUSION}

In short, the implementation of performance appraisal in colleges and strengthening the cost management of human resources not only need to consider the proportion of the whole pay system, but also have to carry out an overall design with the cost of human resources. On the one hand, the expectations of teachers should be considered in order to attract and retain talents. On the other hand, the economic capacity and human resource costs and benefits of the college should be taken into 
account. Only overall planning can achieve the win-win situation of colleges and teachers.

\section{REFERENCES}

[1] Lin Mei. On the strategy of human resource cost management in colleges and universities [J], Journal of Juamjusi Education Institute,2012(07)

[2] Qian Xiaohong. Discussion on the scientific method of human resource cost management in colleges and universities [J]. Research on Higher Education in China,2007(8):85-87
[3] Wang Guoping, Wu Liu. Human resources management of university teachers from the perspective of value management[J], Higher Architectural Education,2013,22(6):8-14

[4] Liu Yan. Significance and approach of implementing human resource cost accounting in colleges and universities [J]. Journal of Hunan City University,2010(06)

[5] Yu Wensheng. A review of the researches on the reform of performance pay in colleges and universities [J], Journal of Sichuan University of Science and Engineering (SOCIAL SCIENCE EDITION),2012,27(1):68 